\title{
Usage of Facebook among Open Education Students
}

\author{
Fikret Er, Harun Sönmez, Sinan Aydin, Gül Er \\ Anadolu University, Eskişehir, Turkey
}

\begin{abstract}
Facebook has become a widespread social network site around the world. As of January 2017, it is estimated that there are more than 1.86 billion monthly active Facebook users. In Europe, there are over 300 million people on Facebook. Facebook's user-friendliness attracts educators, especially for online learning, to use it for educational purposes. Use of Facebook may break the walls of a classroom to a wider audience which is dynamic. Anadolu University, Eskişehir - Turkey, Open and Distance Education System is the first institution in Turkey that offers higher education through contemporary distance education model. There are approximately 1.400.000 students enrolled to the open education programs offered by Anadolu University. In this study, using Bergen Facebook Addiction survey, an analysis of the Facebook addiction of the students who are already enrolled in one of the open education programs offered by Anadolu University is investigated. Statistical analysis of the data is done by using exploratory data analysis techniques.
\end{abstract}

\section{Introduction}

Facebook was founded on $4^{\text {th }}$ of February in 2004. According to Facebook's own Facebook page, the mission of the Facebook is "to give people the power to share and make the world more open and connected. People use Facebook to stay connected with friends and family, to discover what's going on in the world, and to share and express what matters to them"[1]. Around the world, it is estimated that there are more than 1.86 billion monthly active Facebook users and In Europe, over 307 million people on Facebook [2]. Young and old, lots of people use Facebook for social interaction. Facebook opens up the boundaries between people and brings people from all over the world together. One of the main advantages of Facebook is that it allows users to create specific pages with different purposes. Students may create a page for sharing homework, a lecturer may create a page to provide extra information for students of a specific course, universities create pages to encourage students to get a degree from their institutions. Average time spent per Facebook visit is 20 minutes [2], whereas according to American time use survey results for 2015 , average hours per day spent for reading for males in United states is 26 minutes on weekdays and 31 minutes on weekends and holidays [3]. There are numerous studies in literature related with Facebook and its use in education.

In this study, The Bergen Facebook Addiction Scale [4], namely BFAS, is used to measure the Facebook addiction levels of open education students enrolled in programs offered by Anadolu University, Turkey.

\section{Literature review}

There are many studies related with Facebook and its usage among scholars. Some of the studies are summarized as follows.

Andreassen et all. developed a Facebook addiction scale, known as Bergen Facebook Addiction Scale [4]. The Bergen Facebook Addiction Scale (BFAS), initially a pool of 18 items, three reflecting each of the six core elements of addiction (salience, mood modification, tolerance, withdrawal, conflict, and relapse), was constructed and administered to 423 students together with several other standardized self-report scales (Addictive Tendencies Scale, Online Sociability Scale, Facebook Attitude Scale, NEO-FFI, BIS/BAS scales, and Sleep questions). That item within each of the six addiction elements with the highest corrected item-total correlation was retained in the final scale. The factor structure of the scale was good $($ RMSEA $=.046$, CFI $=.99)$ and coefficient alpha was .83 . The 3 -week test-retest reliability coefficient was .82 . The scores converged with scores for other scales of Facebook activity. In our study, the Bergen Facebook addiction scale is used.

Jafarkarami et all. study Facebook addiction among Malaysian students [5]. This study employed the Bergen Facebook Addiction Scale to investigate Facebook addiction among students. In this study, we selected a sample of 441 students in University Teknologi Malaysia as respondents. Results show that $47 \%$ of the participants were addicted to Facebook. This ratio is almost the same among postgraduate and undergraduate students, and interestingly, among Malaysian and non-Malaysian. Much speculated factors such as religion, level of income, ego strength and locus of control do not show significant influence on the risk of Facebook addiction. Lastly, the results suggest that as people 
spend more time on Facebook, there is a greater chance of addiction.

Grosseck et all. look at Facebook for academic uses [6]. Their paper focuses on how students perceive the use of the social networking site Facebook for academic purposes and how / if they integrate it in their learning, training or other (extra) educational activities. In order to investigate how students are engaged in Facebook academic activities, an online questionnaire was applied to our first-year students in the academic year 2010. They found that the majority of students spend significant time on Facebook more for social uses (to stay in touch with friends and family, to share / tag photos, to engage in social activism, volunteering etc.) and less for academic purposes, even if they take part in discussions about their assignments, lectures, study notes or share information about research resources etc.

Brown et all. investigate the students' online content creation from African university students' perspective [7]. This paper describes the stories of three students who are online creators of content, the social media they utilised; their trajectories; their linkages with career interests; the types of online presences they created, maintained or discontinued into their university lives. As the case studies spanned digital practices that were informal and extracurricular yet peer-supported as well as interestdriven and academically oriented, the pedagogical frame-work of Connected Learning proved an appropriate heuristic. The study shows that being a digital creator gives students a competitive edge in our globally competitive society.

Silver and Matthews studies the usefulness of Facebook following a significant disaster [8]. In their study, with a sample size of 35 , an F3 tornado that impacted the community of Goderich, Ontario, on 21 August 2011 provided the opportunity to examine how people utilized Facebook and Facebook groups to seek out information, self-organize, and provide support. The results in their study demonstrate that Facebook was a highly influential source of information and support, particularly in the immediate aftermath of the disaster. Although misinformation and gossip occurred, the tendency was for the group to self-moderate inaccurate information. Public engagement by local officials may further reduce misinformation and encourage public confidence. The results also show that GOTVS activity significantly declined after two weeks. This abrupt decrease in public attention suggests that the window for engagement by public officials is narrow. As such, officials should have a social media plan in place so that they may engage with the public during the critical response phase when their participation may yield the greatest benefit. Finally, their research underscores the potential for analysing Facebook content using computer-assisted content analysis, a method that may be of interest across the social sciences.

Østergaard investigates why the use of social media may cause mental disorder [9]. In their paper, they state that if the use of social media such as Facebook does compromise mental health, we may be facing a global epidemic of mental disorders, which probably has its largest impact on the younger generations that use these applications the most [10]. Therefore, the psychiatric field must take this possibility very seriously and conduct further studies on the effect of social media on mental health, and ways to mitigate this effect if it is indeed a harmful one. One way to do this could be to stress again and again - for children and adolescents in particular that social media is based on highly selected and positively biased projections of reality that should not be taken at face value.

Brunborg et all. investigate social media use and episodic heavy drinking among adolescents [11]. In their study, the main objective is stated as "Little is known about the consequences of adolescent social media use". The current study estimated the association between the amount of time adolescents spend on social media and the risk of episodic heavy drinking. In the study, 851 Norwegian middle and high school students ( $46.1 \%$ boys) are investigated. As a result, it is shown that greater amount of time spent on social media was associated with greater likelihood of episodic heavy drinking among adolescents (OR 1/4 1.12, 95\% CI (1.05, 1.19), p 1/4 0.001 ), even after adjusting for school grade, impulsivity, sensation seeking, symptoms of depression, and peer relationship problems. The results from the current study indicate that more time spent on social media is related to greater likelihood of episodic heavy drinking among adolescents.

Campisi et all. study whether anxiety-inducing Facebook behaviour is associated with higher rates of upper respiratory infection in college-aged users [12]. In the study, it is stated that exposure to chronic stress can suppress immune function and increase susceptibility to infection. Recent evidence indicates that social network use (e.g., Facebook) can serve as a chronic stressor to some users and contribute to poor health, however, mechanisms underlying these interactions remain unclear. In the current study, we investigated if Facebook user behaviour might help start to explain interactions between Facebook use, stress and health. In this prospective study, healthy college students completed online questionnaires assessing Facebook use, health and then were followed for 10 weeks to track incidence of upper 
respiratory infection (URI). Subjects who reported that Facebook provoked anxiety/stress demonstrated a significantly higher number of URI than those not reporting Facebook-induced anxiety/ stress and having more Facebook friends was associated with increased anxiety/stress and the number of URI. Users who demonstrated anxiety regarding their Facebook use were more likely to demonstrate a pattern of increased number of log-ins to Facebook/day and these anxiety-linked behaviour patterns were associated with poorer health. The other health practices and psychological processes assessed (e.g., physical activity levels, sleep, social support) do not appear to explain these associations. These results suggest an association between specific Facebook use, psychological anxiety and health might exist.

\section{Data and Method}

The main purpose of this study is to investigate the addiction levels of Open Education system students in Anadolu University Turkey to Facebook. In order to find the level of addiction to Facebook, Bergen Facebook addiction scale (BFAS) is used [4]. There are 6 questions in BFAS to answer. In BFAS, people are asked to answer "how often during last year have you experienced the following....":

Question 1. Spent a lot of time thinking about Facebook or planned use of Facebook?

Question 2. Felt an urge to use Facebook more and more?

Question 3. Used Facebook in order to forget about personal problems?

Question 4. Tried to cut down on the use of Facebook without success?

Question 5. Become restless or troubled if you have been prohibited from using Facebook?

Question 6. Used Facebook so much that it has had a negative impact on your job/studies?

Respondents have 5 options to choose from ranging between very rarely to very often. The original study of BFAS does not provide specific cut-off scores for a categorization of problems with Facebook addiction [4]. They suggest two approaches: either entail the use of a polythetic scoring scheme (e.g., scoring 3 or above on at least four of the six items), or a more conservative approach could be to use a monothetic scoring key (e.g., scoring 3 or above on all six items). In this study, the categorization of Facebook addiction is created by the following scale: If a student gets a score between 0 and 10 , this student is classified as "Normal Person", If students' score is between 11 and 14, student is classified as "Possible Facebook
Addict", and if students' score is 15 or more, the student is classified as "Facebook Addict".

The population in this study is the students who registered into one of the open and distance education programs offered in Anadolu University Open Education System, Turkey. In order to explain the main structure of the student body of Anadolu University, a short explanation of the Anadolu University Open Education System can be given as follows.

The Faculty of Open Education at Anadolu University was established in 1982-1983 academic year. It is the first institution in Turkey that provides Open and Distance Education for people who are not able to continue formal university education. In 2016-2017 academic year, there were approximately $1,400,000$ students enrolled to one of the open education programs offered in Anadolu University. Anadolu University Open and Distance Education system is also available for people who can speak and write in Turkish living outside of Turkey. Nowadays, Anadolu University offers different degree programs in the following countries: Turkish Republic of Northern Cyprus, Western Europe, Azerbaijan, Macedonia, Kosovo, Albania, BosniaHerzegovina and United States of America. Also, starting from 2017-2018 academic year, there are two new programs offered in English and one program in Arabic. The main mission of Anadolu University is to reach students, who are able to read and write in Turkish and English and are not able to get a formal university education for whatever the reason and give them the opportunity to have a diploma.

In 1993, the structure of the open education system in Anadolu university was changed and Faculty of Business Administration and Faculty of Economics were established within the system to offer four-year undergraduate degrees in related fields.

Main teaching material is the printed book of the course written by the leading academics on the subject in Turkey and abroad. The curriculum of the open education programs is the same as their undergraduate counterparts. Therefore, a student from a formal education may move on to the system without big difficulties and may finish their program and get their degrees. All the degrees from Anadolu University are accredited with the necessary associations. Anadolu University offers its open education students face-to-face classes for some difficult courses such as mathematics and finance in almost every city in Turkey with the collaboration of local universities in those cities. Students are provided with extra materials to understand the course via e-seminars, television programs from a 
nationwide free TV channel TRT School, and ecampus interactive learning environment. Around Turkey, in every city, there are bureaus for students to get in contact with Anadolu University and obtain their class books and get official papers.

The student body of Open Education is not a unified one, it is rather a heterogeneous group. There are students from every age group starting from 18 up to above $70.41 \%$ of the students' age is above 28 years. In Anadolu University Open Education system, there are approximately 25,000 students with disabilities. Those students with vision problems account for $43 \%$. Therefore, the system allows the handicapped students to have a chance to obtain a university diploma.

At the moment, in Anadolu University Open Education system, there are 3 faculties for teaching via open and distance education method, namely Open Education, Economics and Business Faculties.

Anadolu University provides a portal for lecturers to use for data collection. The survey is put on to this portal and students are invited to fill out the survey form. At the end of the survey, once a student submits his/her answer, then the Facebook addiction of the student is shown on the screen. The survey system used in this study ensures that the students to fill-out the survey is chosen randomly. The survey system randomly chooses students from different cities. The number of students chosen in the sample is proportional to the total number of students in a given city.

The sample size in this study is 8,728 students. The level of significance for statistical analysis is chosen as $0.05 \%$. In order to analyse the data set, descriptive statistical methods, chi-square independence test, and one-way analysis of variance are carried out.

\section{Results}

In this study, the BFAS is used for measuring Facebook addiction levels of the students. The number of students who answered the BFAS questions is 8,728 from different cities of Turkey. Only the students who reside in Turkey are included in this study. The students who live permanently outside of Turkey but registered to the Anadolu University open and distance education system are not included in this study.

The reliability of the answers given to the survey is measured by Cronbach's alpha which is 0.903 . Therefore, it can be said that the answers given to the survey by the students are highly reliable.

The distribution of the students in sample according to the faculty is given in Table 1. The age distribution of the students in the survey is given in
Table 2. Table 1 shows that $44.5 \%$ of the students are from Open Education Faculty in which most of the offered programs are 2 years. The remaining $55.5 \%$ of the students are from the two other faculties in which the degree programs are generally four years. Table 2 shows that $57.2 \%$ of the students are 30 or less years old. The percentage of the students who are over 41 years is 15.4 . As Table 2 indicates there are students from different age groups in the sample.

Table 1 . The number of students according to faculty

\begin{tabular}{|l|l|l|}
\hline Faculty & Frequency & Percent \\
\hline Business Faculty & 2177 & 24.9 \\
\hline Economics Faculty & 2668 & 30.6 \\
\hline $\begin{array}{l}\text { Open Education } \\
\text { Faculty }\end{array}$ & 3883 & 44.5 \\
\hline Total & 8128 & 100 \\
\hline
\end{tabular}

Table 2. Age distribution of the students

\begin{tabular}{|l|l|l|}
\hline Age & Frequency & Percent \\
\hline 20 and less & 160 & 1.8 \\
\hline $21-25$ & 2523 & 28.9 \\
\hline $26-30$ & 2309 & 26.5 \\
\hline $31-35$ & 1360 & 15.6 \\
\hline $36-40$ & 1027 & 11.8 \\
\hline $\mathbf{4 1 - 4 5}$ & 649 & 7.4 \\
\hline $\mathbf{4 6}-\mathbf{5 0}$ & 435 & 5.0 \\
\hline $\mathbf{5 0}$ and over & 265 & 3.0 \\
\hline Total & 8728 & 100 \\
\hline
\end{tabular}

Figure 1 shows the histogram of GPA distribution of the students who participated in the study. As it can be seen from the histogram, the students are generally successful in their programs. The students are expected to have a GPA more than 2.0 out of 4.0 in order to graduate. The mean GPA is 2.38 in our sample data.

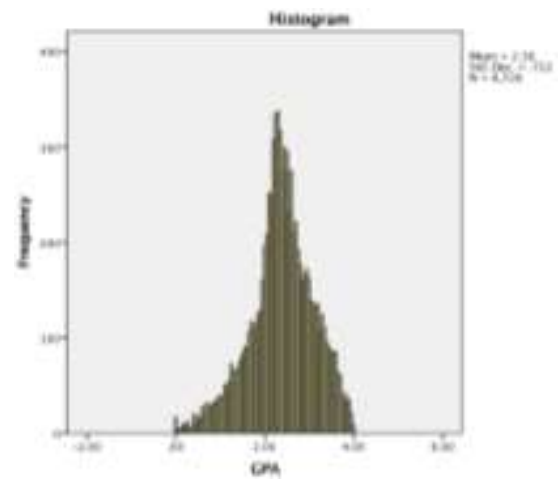

Figure 1. Histogram of GPA 
The first question of BFAS is "spent a lot of time thinking about Facebook or planned use of Facebook?". The distribution of the answers as a pie chart is given in Figure 2. The opinions of the students for question 1 are mainly centered on rarely and very rarely.

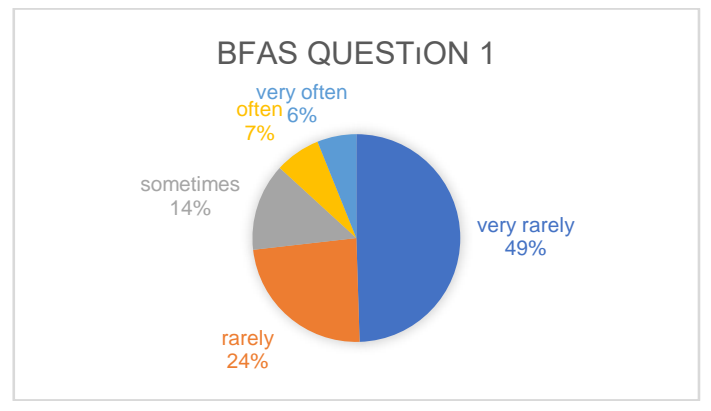

Figure 2. Pie chart for BFAS Question 1

The second question of BFAS is "felt an urge to use Facebook more and more?". The distribution of the answers as a pie chart is given in Figure 3. The highest frequency is for very rarely with a percentage of 54 .

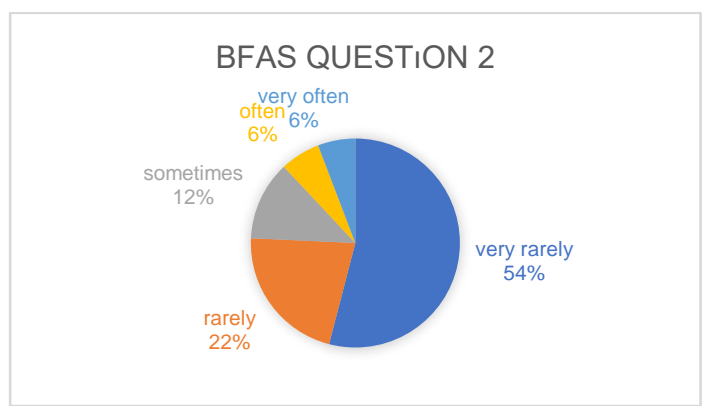

Figure 3. Pie chart for BFAS Question 2

The third question of BFAS is "used Facebook in order to forget about personal problems?". The distribution of the answers as a pie chart is given in Figure 4. In here, very rarely option gets a percentage of 58 .

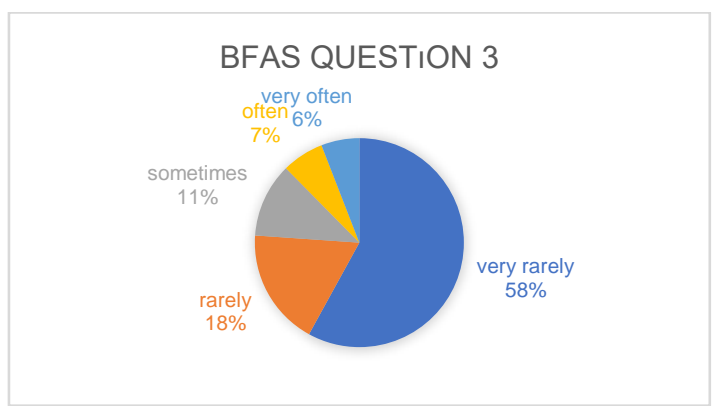

Figure 4. Pie chart for BFAS Question 3
The fourth question of BFAS is "tried to cut down on the use of Facebook without success?". The distribution of the answers as a pie chart is given in Figure 5.

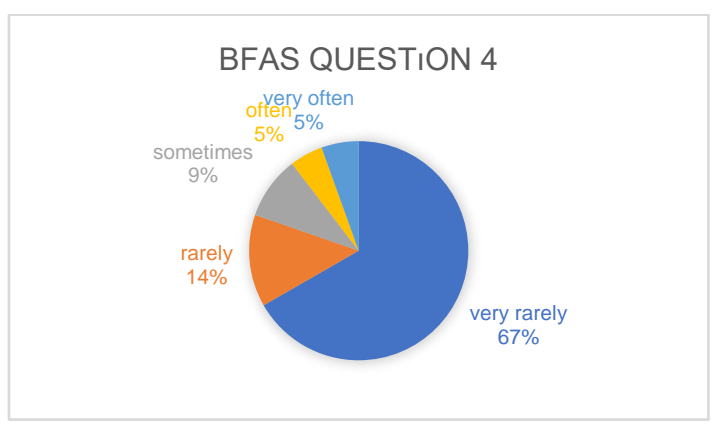

Figure 5. Pie chart for BFAS Question 4

The fifth question of BFAS is "become restless or troubled if you have been prohibited from using Facebook?". The distribution of the answers as a pie chart is given in Figure 6.

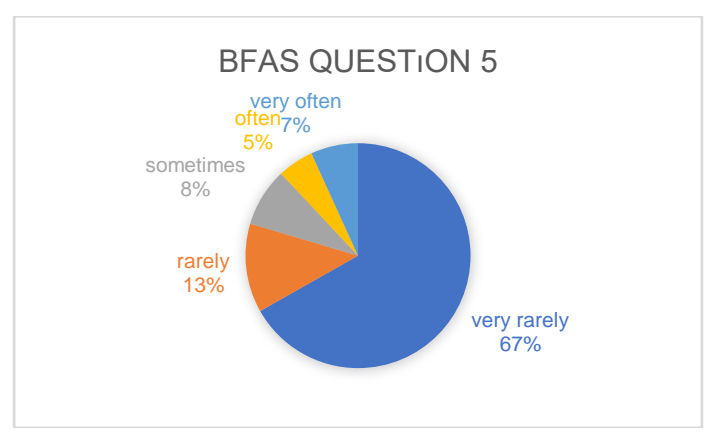

Figure 6. Pie chart for BFAS Question 5

The sixth question of BFAS is "used Facebook so much that it has had a negative impact on your job/studies?". The distribution of the answers as a pie chart is given in Figure 7.

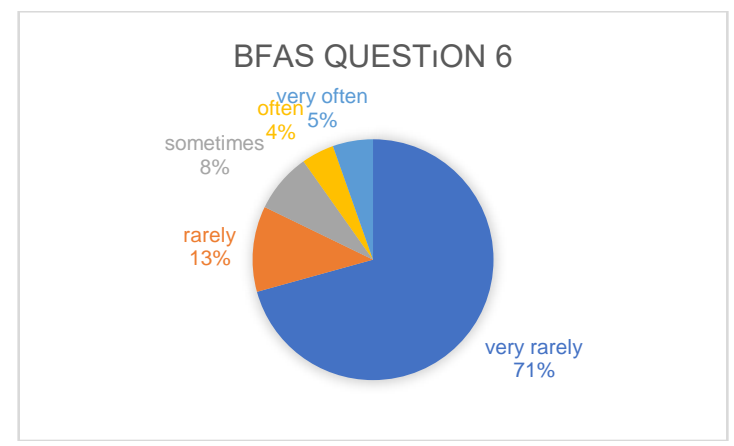

Figure 7. Pie chart for BFAS Question 6 
The Figures from 2 to 7 show that the students usually preferred to answer as rarely or very rarely. Using the BFAS scaling the addiction levels of students to Facebook is classified into three categories and given in Table 3. According to Table $321.3 \%$ of the students may be classified as Facebook addicts.

Table 3. Percentage of students for Facebook addiction

\begin{tabular}{|l|r|r|}
\hline \multicolumn{1}{|c|}{ Addiction } & Frequency & Percent \\
\hline Normal Person & 5556 & 63.7 \\
\hline Possible Facebook Addict & 1317 & 15.1 \\
\hline Facebook Addict & 1855 & 21.3 \\
\hline Total & 8728 & 100 \\
\hline
\end{tabular}

Table 4. Frequency distribution for Facebook addiction level "Normal Person" vs. age

\begin{tabular}{|l|r|}
\hline \multicolumn{1}{|c|}{ Age } & Normal Person \\
\hline$<=20.00$ & $1.70 \%$ \\
\hline $\mathbf{2 1 . 0 0}-\mathbf{2 5 . 0 0}$ & $25.80 \%$ \\
\hline $\mathbf{2 6 . 0 0}-\mathbf{3 0 . 0 0}$ & $25.10 \%$ \\
\hline $\mathbf{3 1 . 0 0}-\mathbf{3 5 . 0 0}$ & $16.40 \%$ \\
\hline $\mathbf{3 6 . 0 0}-\mathbf{4 0 . 0 0}$ & $13.50 \%$ \\
\hline $\mathbf{4 1 . 0 0}-\mathbf{4 5 . 0 0}$ & $8.30 \%$ \\
\hline $\mathbf{4 6 . 0 0}-\mathbf{5 0 . 0 0}$ & $5.80 \%$ \\
\hline $\mathbf{5 0 . 0 0 +}$ & $3.40 \%$ \\
\hline Total & $100.00 \%$ \\
\hline
\end{tabular}

Table 5. Frequency distribution for Facebook addiction level "Possible Facebook Addict" vs. age

\begin{tabular}{|rr|}
\hline \multicolumn{1}{|c|}{ Age } & Possible Facebook Addict \\
\hline$<=20.00$ & $2.40 \%$ \\
\hline $21.00-25.00$ & $32.10 \%$ \\
\hline $26.00-30.00$ & $26.10 \%$ \\
\hline $31.00-35.00$ & $15.80 \%$ \\
\hline $36.00-40.00$ & $9.20 \%$ \\
\hline $41.00-45.00$ & $7.60 \%$ \\
\hline $46.00-50.00$ & $3.40 \%$ \\
\hline $50.00+$ & $3.40 \%$ \\
\hline Total & $100.00 \%$ \\
\hline
\end{tabular}

Table 6. Frequency distribution for Facebook addiction level "Normal Person" vs. age

\begin{tabular}{|l|r|}
\hline \multicolumn{1}{|c|}{ Age } & Facebook Addict \\
\hline$<=20.00$ & $1.90 \%$ \\
\hline $21.00-25.00$ & $35.80 \%$ \\
\hline $26.00-30.00$ & $30.70 \%$ \\
\hline $31.00-35.00$ & $13.10 \%$ \\
\hline $36.00-40.00$ & $8.50 \%$ \\
\hline $41.00-45.00$ & $4.70 \%$ \\
\hline $46.00-50.00$ & $3.60 \%$ \\
\hline $50.00+$ & $1.70 \%$ \\
\hline Total & $100.00 \%$ \\
\hline
\end{tabular}

In Table 4, 5, and 6, frequency distributions are given for the variables Facebook addiction level and age. There are eight categories for the age variable.

A chi-square independence test between age and Facebook addiction is investigated. According to chisquare independence test there is a statistically significant dependency between age and Facebook addiction levels (Pearson Chi-square $=179.43$, d.f. $=$ $14, \mathrm{p}=0.00)$.

A concise contingency table of percentages is given in Table 7 between age and Facebook addiction levels using Tables 4, 5, and 6. The Table 7 is organized that the column values adds up to $100 \%$.

Table 7. A concise contingency Table for Facebook addiction levels' distribution by some age groups.

\begin{tabular}{|l|r|r|r|}
\hline \multicolumn{1}{|c|}{ Age } & $\begin{array}{c}\text { Normal } \\
\text { Person }\end{array}$ & $\begin{array}{c}\text { Possible } \\
\text { Facebook } \\
\text { Addict }\end{array}$ & $\begin{array}{c}\text { Facebook } \\
\text { Addict }\end{array}$ \\
\hline $\begin{array}{l}\text { Less than or } \\
\text { equal } 30\end{array}$ & $52.6 \%$ & $60.6 \%$ & $68.4 \%$ \\
\hline $\begin{array}{l}\text { between } 31 \text { and } \\
40\end{array}$ & $29.9 \%$ & $25.0 \%$ & $27.4 \%$ \\
\hline more than 40 & $17.5 \%$ & $14.4 \%$ & $10.0 \%$ \\
\hline Total & $100.0 \%$ & $100.0 \%$ & $100.0 \%$ \\
\hline
\end{tabular}

Table 7 shows that $68.4 \%$ of the Facebook addicts are from less than or equal to 30 years old age group whereas only $10 \%$ of the Facebook addicts are from more than 40 years old age group. The percentage of possible Facebook addicts increases to $14.4 \%$ for students whose age is 40 years or more. In Table 8, a contingency table for percentages of each age group given in Table 2 is classified in terms of their Facebook addiction levels. Table 7 and Table 8 show that as the age gets younger the Facebook addiction level increases. The highest 
Facebook addiction percentage, 26.30, is obtained for the $21-25$ age group. This is followed by, with $24.60 \%, 26-30$ age group.

Table 8. A contingency table for the distribution Facebook addiction levels for each age group

\begin{tabular}{|c|c|c|c|c|}
\hline Age & $\begin{array}{c}\text { Normal } \\
\text { Person }\end{array}$ & $\begin{array}{c}\text { Possible } \\
\text { Facebook } \\
\text { Addict }\end{array}$ & $\begin{array}{c}\text { Facebook } \\
\text { Addict }\end{array}$ & Tot. \\
\hline$<=20$ & $58.10 \%$ & $19.40 \%$ & $22.50 \%$ & 100 \\
\hline $21-25$ & $56.90 \%$ & $16.80 \%$ & $26.30 \%$ & 100 \\
\hline $26-30$ & $60.50 \%$ & $14.90 \%$ & $24.60 \%$ & 100 \\
\hline $31-35$ & $66.80 \%$ & $15.30 \%$ & $17.90 \%$ & 100 \\
\hline $36-40$ & $72.90 \%$ & $11.80 \%$ & $15.30 \%$ & 100 \\
\hline $41-45$ & $71.20 \%$ & $15.40 \%$ & $13.40 \%$ & 100 \\
\hline $46-50$ & $74.30 \%$ & $10.30 \%$ & $15.40 \%$ & 100 \\
\hline $50+$ & $70.90 \%$ & $17.00 \%$ & $12.10 \%$ & 100 \\
\hline
\end{tabular}

In order to find out if there is a statistically significant difference for the Facebook addiction scores of students from different faculties, a one-way analysis of variance is carried out. In Table 9, the analysis of variance table is given.

Table 9. Analysis of variance table for Facebook addiction scores for three faculties

\begin{tabular}{lr|r|r|r|r} 
& \multicolumn{1}{c}{$\begin{array}{c}\text { Sum of } \\
\text { Squares }\end{array}$} & \multicolumn{1}{c|}{ d.f. } & Square & \multicolumn{1}{c|}{ F } & Sig. \\
\hline $\begin{array}{l}\text { Between } \\
\text { Groups }\end{array}$ & 1541.505 & 2 & 770.752 & 22.592 & 0.0 \\
\hline $\begin{array}{l}\text { Within } \\
\text { Groups }\end{array}$ & 297664.174 & 8725 & 34.116 & & \\
\hline Total & 299205.679 & 8727 & & & \\
\hline
\end{tabular}

The Table 9 shows that, using statistical significance level as $0.05 \%$, it can be said that there is a statistically significant difference $(\mathrm{p}=0.0<$ $\alpha=0.05$ ) between faculties' BFAS scores. Therefore, these three faculties should be investigated separately in terms of students Facebook addiction levels.

\section{Discussion}

Facebook becomes more and more a part of persons' daily life routine. Especially, the modern cellular phones make connection to Facebook extremely easy. As a social media tool, Facebook is a very successful online environment growing daily. There are still many people who are trying to stay away from the online social networks but as the technology gets better it looks like it is inevitable that the people will be in contact, to some degree, with some sort of social networks in their life time.

Open education is a big revolution in Turkey since it has opened up the doors of a university degree for many people who had not have an opportunity of obtaining a diploma from an incampus education. Turkey is a very big country and in some rural areas people still depend on man power to turn around their daily life, so some young people are forced to stay at home rather than pursuing their dreams of getting a university diploma. Open Education system of Anadolu University has already provided many opportunities to those students who may not get a diploma by conventional methods.

Anadolu University Open Education system was using a postal service to send the books to the students at the beginning, but nowadays by using local branches spread around Turkey, students are able to get in touch with a representative of Anadolu University and be able to pick up books. The recent developments in technology provided new opportunities to Anadolu University in order to improve services provided to the students. One of the improvements was to use social network sites such as Facebook to get in touch more with students and also give a chance an interaction between students. Anadolu University Open Education Faculty Media team created a specific Facebook site called Anadolum to improve interaction between students and open education system. A small portion of the Facebook page is given in Figure 8. All the announcements related with the system, such as announcements about exams, exam results, new programs, happy occasions related with students are made in this Facebook page.

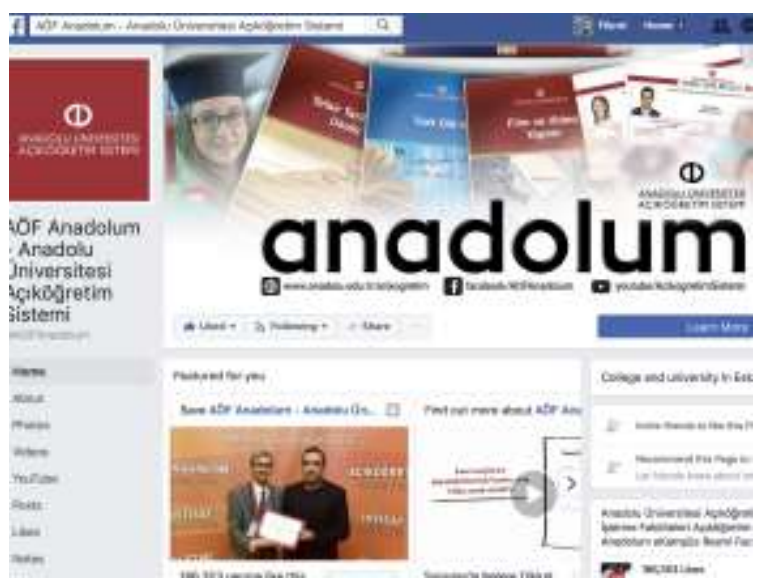

Figure 8. Anadolum Facebook page 
Figure 9 shows a Facebook page created for a 2year program, Photography and Cinematography, of Anadolu University.

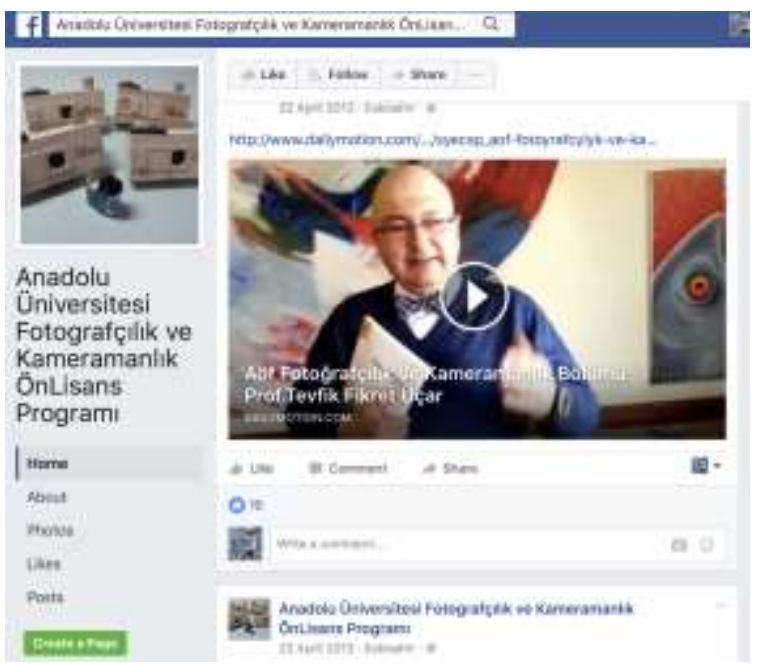

Figure 9. Facebook page for a 2-year program

In Figure 9, it can be seen that there is a video of a lecturer related with the program. The program Facebook pages are extremely useful for those students registered to these programs. Students can join these Facebook pages and interact with each other therefore an in-campus interaction environment may be carried on to a virtual environment.

In this study, Facebook addiction levels of the students are measured by Bergen Facebook Addiction survey. It allowed us to see that the Facebook addiction level increases as the age goes younger. For the older students, the Facebook addiction levels are still low. But it should be noted that Facebook social network site is still a young environment to reach older people. Nowadays the technology moves a lot faster than in the past and length of time for people to pay attention to Facebook is not known at the moment, but using the results of this study, the management of open education system in Turkey, and around the world in that manner, may target the young people from Facebook and get their attention for a diploma.

\section{Conclusion}

In this study, the Facebook addiction of Open Education students of Anadolu University, Turkey is measured by Bergen Facebook Addiction Scale [4]. Overall, $63.7 \%$ of the students are not Facebook addicts whereas the remaining of the students are addicted to Facebook at some degree. Furthermore, since Anadolu University provides open and distance education programs through three different faculties, a comparison of the faculties for Bergen scores are investigated. Using one-way Anova, it is found that the Bergen scores of the faculties are statistically significantly different. Business Faculty students get the highest average, followed by Economics Faculty students. The Open Education Faculty students get the lowest average score in between these faculties.

The highest percentage for Facebook addiction in terms of age is found as $26.3 \%$ for $21-25$ years old students. The highest percentage for possible Facebook addict is found as $19.4 \%$ for less than 20 years old students.

Bergen Facebook Addiction scale [4] is a useful tool to find out how much a person may be addicted to Facebook, therefore it has been used in this study. This study shows that there are students who are Facebook addicts and the addiction levels to Facebook are changing by the age of the student and the Faculty that the students are enrolled to.

\section{References}

[1] Facebook, (2004) "about facebook", [Internet] http://www.facebook.com (Access Date: 25 January 2017).

[2] Zephoria, (2016) "The top 20 valuable Facebook statistics - Updated February 2017", [Internet], https://zephoria.com/top-15-valuable-facebook-statistics/ (Access Date: 20 February 2017).

[3] Bureau of Labor Statistics, (2017) "Time spent in leisure and sports activities for the civilian population by selected characteristics, 2015 annual averages, [Internet], https://www.bls.gov/news.release/atus.t11.htm, (Access Date: 25 February 2017)

[4] C.S. Andreassen, T. Torsheim, G.S. Brunborg, and S. Pallesen (2012) "Development of a Facebook addiction scale", Psychological Reports, 110, No.2.

[5] H. Jafarkarami, A.T.H. Sim, R. Saadatdoost, and J.M. Hee (2016) "Facebook addiction among Malaysian students", International Journal of Information and Education Technology, Volume 6, No.6.

[6] G. Grosseck, R. Bran, L. Tiru (2011) "Dear teacher, what should I write on my wall? A case study on academic uses of Facebook" Procedia Social and Bevioral Sciences, Volume 15, 1425-1430.

[7] C. Brown, L. Czerniewicz, and T. Noakes (2016) " Online content creation: looking at students' social media practices through a Connected Learning lens", Learning, Media and Technology, Volume 41, No.1.

[8] A. Silver, and L. Matthews (2017) "The use of Facebook for information seeking, decision support, and self-organization following a significant disaster", Information, Communication \& Society, Vol: 20:11, 16801697. 
[9] SD Østergaard (2017) "Taking Facebook at face value: why the use of social media may cause mental disorder", Acta Psychiatr Scand., Vol: 136(5), 439-440.

[10] HB. Shakya, NA. Christakis (2017) "Association of Facebook use with compromised well-being: a longitudinal study”, Am J Epidemiol, Vol: 185, 203-211.

[11] GS. Brunborg, JB Andreas, and E. Kvaavik. (2017) "Social media use and episodic heavy drinking among adolescents", Psychological Reports, Vol: 120 120: 475490.

[12] J. Campisi, J. May, K. Burch, K. Larson, J. Doscher, S. Doherty, K. Isaacson, K. Sebring, and A. Gahan (2017) "Anxiety-inducing Facebook behavior is associated with higher rates of upper respiratory infection in college-aged users" Computers in Human Behavior, Vol:76, 211-217.

\section{Acknowledgements}

This study is funded by Contract No 1601E011 from the Anadolu University Scientific Research Projects (BAP), Turkey, 2017. 